\title{
Total arch replacement using antegrade cerebral perfusion
}

\author{
Yutaka Okita, MD, PhD, Kenji Okada, MD, PhD, Atsushi Omura, MD, Hiroya Kano, CE, \\ Hitoshi Minami, MD, PhD, Takeshi Inoue, MD, and Shunsuke Miyahara, MD
}

Objective: The technical details of total arch replacement using antegrade cerebral perfusion are presented.

\begin{abstract}
Methods: From January 2002 to May 2012, 423 consecutive patients (mean age, $69.2 \pm 13.1$ years) underwent total arch replacement using antegrade selective cerebral perfusion through a median sternotomy. Acute aortic dissection was present in 81 patients (19.1\%; 75 type A, 6 type B), and a shaggy aorta was present in 37 patients $(8.7 \%)$. Emergency/urgent surgery was required in 135 patients $(31.9 \%)$. Our current approach included meticulous selection of the arterial cannulation site and type of arterial cannula, antegrade selective cerebral perfusion, maintenance of the minimal tympanic temperature between $20^{\circ} \mathrm{C}$ and $23^{\circ} \mathrm{C}$, early rewarming immediately after distal anastomosis, and maintenance of the fluid balance at less than $1000 \mathrm{~mL}$ during cardiopulmonary bypass. A woven Dacron 4-branch graft was used in all patients.
\end{abstract}

Results: The overall hospital mortality was 4.5\% (19/423): 9.6\% (13/135) in urgent/emergency surgery cases and $2.1 \%(6 / 288)$ in elective cases. Permanent neurologic deficits occurred in 3.3\% patients (14/423). Prolonged ventilation was necessary in 57 patients $(13.4 \%)$. A multivariate analysis demonstrated the risk factors for hospital mortality to be age (octogenarian; odds ratio, $4.45 ; P=.02$ ), brain malperfusion (odds ratio, 22.5; $P=.002$ ), and cardiopulmonary bypass time (odds ratio, $1.06 ; P=.04$ ). The follow-up was completed in $97.2 \%$ of patients (mean, $29 \pm 27 ; 1-126$ ) and included 2.3 patients per year. Survival at 5 and 10 years after surgery was $79.6 \% \pm 3.3 \%$ and $71.2 \% \pm 5.0 \%$, respectively. In the acute A dissection group, the 10 -year survival was $96.6 \% \pm 2.4 \%$. In the elective nondissection group, the 5- and 10 -year survivals were $80.3 \% \pm 4.2 \%$ and $76.1 \% \pm 5.7 \%$, respectively.

Conclusions: Our current approach for total aortic arch replacement is associated with low hospital mortality and morbidity, thus leading to a favorable long-term outcome. (J Thorac Cardiovasc Surg 2013;145:S63-71)

With the aging of society, the number of patients who have aortic disease has been increasing steadily. Awareness regarding aortic disease has played a major role in its detection, and the innovational refinement of diagnostic tools for aortic disease has been a prerequisite for improving the outcome of patients. The results of surgery also have been improving with advances in surgical technologies, improved knowledge of the disease, use of sealed grafts, improved protection of the central nervous system, development of stent grafting, and the continuous efforts of the surgeons. ${ }^{1-4}$ According to a survey by the Japanese Association for Thoracic Surgery, since 1984 the annual number of operations for the thoracic aorta has dramatically increased from 712 in 1984 to 12,439 in

\footnotetext{
From the Division of Cardiovascular Surgery, Department of Surgery, Kobe University Graduate School of Medicine, Kobe, Japan.

Disclosures: Drs Okita, Okada, Omura, Kano, Minami, Inoue, and Miyahara have nothing to disclose with regard to commercial support.

Read at The American Association for Thoracic Surgery Aortic Symposium, New York, New York, April 26-27, 2012.

Received for publication July 3, 2012; revisions received Aug 10, 2012; accepted for publication Nov 28, 2012; available ahead of print Dec 26, 2012.

Address for reprints: Yutaka Okita, MD, PhD, Division of Cardiovascular Surgery, Department of Surgery, Kobe University Graduate School of Medicine, 7-5-2,

Kusunoki-Cho, Chuo-Ku, Kobe, Hyogo, 650-0017, Japan (E-mail: yokita@med.

kobe-u.ac.jp).

0022-5223/\$36.00

Copyright (c) 2013 by The American Association for Thoracic Surgery

http://dx.doi.org/10.1016/j.jtcvs.2012.11.070
}

$2010 .^{5}$ The 30-day mortality after elective arch replacement decreased to $7.0 \%$, and the hospital mortality after an emergency operation for an acute type A aortic dissection was reported to be $9.2 \%$ in the Japanese 2010 registry. At the same time, the strategies used for treating aortic disease have been improving so that there are now a wide variety of options, including endovascular stent grafting or hybrid stent grafting. ${ }^{6}$ Surgeons should be ready to apply any of these strategies for clinical applications. It is now imperative to devise not only new surgical techniques but also accurate preoperative imaging strategies to assess the aortic pathology, monitor brain perfusion, evaluate the fluid balance during cardiopulmonary bypass (CPB), and assess the impact of pharmacologic interventions for pulmonary protection, which may lead to further improvement in the short- and long-term outcomes of the treatment of aortic arch disease. The purpose of this report is to describe our surgical technique for total arch replacement.

\section{PATIENTS AND METHODS}

This study was approved by the Kobe University Graduate School of Medicine Institutional Review Board, and the need for individual consent was waived. From January 2002 to May 2012, 869 patients underwent aortic arch replacement at Kobe University Hospital: 394 patients with ascending aorta to hemiarch replacement, 475 patients with total arch replacement, 70 patients with distal arch replacement, and 30 patients with extensive arch replacement. In this study, 423 patients who underwent 


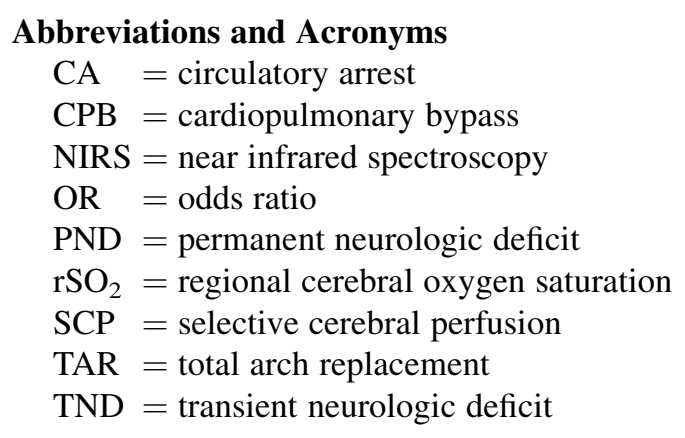

total arch replacement using antegrade cerebral perfusion were investigated. The mean age of the patients was $69.2 \pm 13.1$ years, and 82 $(19.4 \%)$ were aged more than 80 years. The male to female ratio was $313: 110$. The aortic pathology was a nondissection aneurysm in 270 patients $(63.8 \%)$ and an aortic dissection in 153 patients $(36.2 \%)$, including acute type A dissections in 75 patients $(17.7 \%)$ and type B complicated with nondissection aneurysms in 6 patients $(1.4 \%)$. Twenty-nine patients $(6.1 \%)$ had aortitis syndrome, an infected aneurysm, or other complications. A shaggy aortic arch was observed in 37 patients (8.7\%). Surgery was performed on an emergency/urgent basis in 153 patients $(31.9 \%)$. The other conditions included a history of cerebral infarction in 38 patients $(9.0 \%)$, coronary artery disease in 102 patients $(24.1 \%)$, chronic obstructive pulmonary disease in 35 patients $(8.3 \%)$, left ventricular dysfunction (ejection fraction $<40 \%$ ) in 13 patients $(2.7 \%)$, and chronic kidney disease (creatinine $\geq 2.0 \mathrm{mg} / \mathrm{dL}$ ) in 34 patients $(8.0 \%)$. The average European System for Cardiac Operative Risk Evaluation was $8.8 \pm 3.1$ (Table 1).

\section{Surgical Approach}

Our current approach has been (1) meticulous selection of the arterial cannulation site and type of arterial cannula; (2) antegrade selective cerebral perfusion (SCP) for cerebral protection; (3) whole-body hypothermia with minimal tympanic temperatures between $20^{\circ} \mathrm{C}$ and $23^{\circ} \mathrm{C}$ and minimal rectal temperatures at less than $30^{\circ} \mathrm{C}$; (4) early rewarming after distal anastomosis with antegrade SCP flow adjustment while monitoring brain oxygenation by near infrared spectroscopy (NIRS); and (5) after 2006, thus maintaining a strict fluid balance at less than $1000 \mathrm{~mL}$ by the extracorporeal ultrafiltration method during $\mathrm{CPB}$, with the expectation of more rapid pulmonary functional recovery. ${ }^{7}$

Patients were placed in the supine position, and the diodes of the NIRS were attached on the foreheads bilaterally. For NIRS, we used the INVOS 5100C (Somanetics, Troy, Mich), which provides continuous readings of the regional cerebral oxygen saturation $\left(\mathrm{rSO}_{2}\right)$. The $\mathrm{rSO}_{2}$ readings are expressed as an index, measuring differences from an unknown baseline. An ordinary midsternotomy was applied, and there was no need for extension of the skin incision to the left neck.

Before the patient was placed on $\mathrm{CPB}$, the innominate vein was fully mobilized by dividing several branches to facilitate the exposure of the aneurysm (Figure 1). However, dissection of the aneurysm, aortic arch branches, or vagal nerve was never tried. No taping around the arch or arch vessels was applied (Figure 1). Epiaortic echocardiography scanning was performed in every case. The cannulation site and type of arterial cannulation used for CPB are particularly important. Preoperative CT scanning was performed for every patient, including emergency cases, to assess the atheromatous lesions in the ascending aorta.

Both transesophageal and epiaortic echography were applied to interrogate the ascending aorta and determine the optimal cannulation site
(Figure 2, A). The selected cannulation sites were the ascending aorta/ arch in 320 patients $(75.7 \%)$, the femoral artery in 68 patients $(16.4 \%)$, the axillary artery in 1 patient $(0.2 \%)$, the femoral artery + axillary artery in 8 patients $(1.9 \%)$, and the ascending aorta + femoral artery in 24 patients $(5.7 \%)$. CPB was established with bicaval drainage. The left ventricle was vented through the right upper pulmonary vein. Femoral artery cannulation was applied particularly in patients with aortic dissection. For the diseased ascending aorta/aortic arch, a 24F dispersion arterial cannula (Duraflo II, Edwards Lifesciences LLC, Irvine, Calif) was used in 196 cases $(46.3 \%)$. Other patients had a straight-tip cannula inserted in the ascending aorta (DLP; Medtronic, Inc. Minneapolis, Minn). The tip of the catheter was always set to the aortic valve to avoid direct flow to the arch. All patients received $100 \mathrm{mg}$ of betamethasone sodium phosphate and $100 \mathrm{mg}$ of sivelestat sodium hydrate added to the pump circuit at the initiation of $\mathrm{CPB}$.

After the tympanic temperature had decreased to $23^{\circ} \mathrm{C}$, with a rectal temperature at less than $30^{\circ} \mathrm{C}$, the aortic arch aneurysm was opened while increasing the central venous pressure to $10 \mathrm{~mm} \mathrm{Hg}$ or brief periods of retrograde cerebral perfusion. By using 4 traction sutures, including 3 each at the root of the arch vessels and 1 in the lesser curvature of the arch, the inside of the aortic arch was exposed (Figure 2,B).

Next, antegrade SCP was initiated. A $14 \mathrm{~F}$ or $16 \mathrm{~F}$ balloon-tipped cannula was inserted from inside the aorta into the brachiocephalic artery, and $12 \mathrm{~F}$ cannulae were positioned in the left common carotid and left subclavian arteries. We have routinely used self-inflating serrated-balloon-tipped cannulae (Fuji Systems, Tokyo, Japan). Snaring the neck vessels was strictly prohibited (Figure 3,A). Vigorous stay stitches were applied to secure the cannulae when they were observed to be slipping off (Figure 3, B). After the cannulas were inserted, they were fixed in the right side of the skin edge so they did interfere the exposure of the orifice of the descending aorta. Avoiding cerebral embolism was particularly important in SCP cannulation. For the ostium of severely atherosclerotic arch vessels, the arteriotomy of the arch vessels was extended from the diseased ostium to a relatively clear distal part, so that cannulae were placed in position under direct vision. The antegrade SCP flow was maintained at 10 to $12 \mathrm{~mL} / \mathrm{kg} /$ min using an independent roller pump, and the balloon tip pressure was maintained between 30 and $40 \mathrm{~mm} \mathrm{Hg}$. Myocardial protection was achieved by antegrade or retrograde cardioplegia. Gauze sponges were placed in the aortic root and descending aorta to catch atheromatous debris.

To prevent left recurrent nerve injury, we never dissected the vagal nerve. This procedure also can reduce inadvertent injury of the esophagus. Direct circumferential transection of the proximal end of the descending aorta, distal to the aneurysm, was usually performed starting at the 3 o'clock position (Figure $3, A$ and $C$ ). It is important not to lose the adventitia during this maneuver. Further dissection of the descending aorta, for at least 3 to $5 \mathrm{~cm}$, was necessary to have enough suture bites and to place a Teflon felt strip. The right and left bronchial arteries were usually divided, and the upper intercostal arteries also were sometimes divided to mobilize the descending aorta. The thoracic duct often lies along the descending aorta at this level and should not be injured (Figure 4, $A$ ). We tried to prevent opening the left pleura and inadvertent bleeding from the distal anastomosis, because this may lead to its escape into the deep left pleural cavity, where it can sometimes go unnoticed by the surgeons.

A 25-mm-wide Teflon felt strip was placed around the descending aorta. A sealed 4-branched (10, 8, 8, and $8 \mathrm{~mm}$ ) graft (J graft, Japan Lifeline, Tokyo, or Triplex; Terumo Corp, Tokyo, Japan) was used. An elephant trunk was inserted into the descending aorta in patients with acute type A dissections. The open distal aortic anastomosis was performed with a flexible suction catheter placed inside the graft to collect the blood in the descending aorta; 4-0 monofilament sutures and a $22-\mathrm{mm}$ needle were used. The sutures started at the 9 o'clock position, going counterclockwise (Figure 4, B). Sutures were tied first, and the suture bites were taken to include at least $10 \mathrm{~mm}$. After completing the anastomosis, a 4-0 compacting suture was placed to fasten the Teflon felt (Figure 4,C). 
TABLE 1. Patients

\begin{tabular}{|c|c|c|}
\hline No. of patients & 423 & $(\%)$ \\
\hline Age, $y$, mean \pm SD & $69.3 \pm 13.3(16-94)$ & \\
\hline Octogenarian & 82 & 19.4 \\
\hline Male gender & 313 & 74.0 \\
\hline \multicolumn{3}{|l|}{ Aortic pathology } \\
\hline Aortic dissection & 153 & 36.2 \\
\hline Acute type A dissection & 75 & 17.7 \\
\hline Brain malperfusion & 9 & 2.1 \\
\hline Acute type B dissection & 6 & 1.4 \\
\hline Nondissection & 270 & 63.8 \\
\hline Shaggy aorta & 37 & 8.7 \\
\hline Marfan syndrome & 15 & 3.5 \\
\hline Emergency/urgent & 135 & 31.9 \\
\hline Rupture & 34 & 8.0 \\
\hline Shock status & 12 & 2.8 \\
\hline Diabetes mellitus & 54 & 12.8 \\
\hline Old cerebral infarction & 32 & 7.6 \\
\hline Coronary artery disease & 92 & 21.7 \\
\hline $\operatorname{LVEF}(\leq 40 \%)$ & 12 & 2.8 \\
\hline COPD & 33 & 7.8 \\
\hline Chronic kidney disease (creatinine $\geq 2.0$ ) & 29 & 6.9 \\
\hline euroSCORE & $8.8 \pm 3.1$ & \\
\hline \multicolumn{3}{|l|}{ Concurrent procedure } \\
\hline Coronary artery bypass grafting & 92 & 21.7 \\
\hline Aortic root replacement (valve sparing) & 16 & 3.8 \\
\hline Aortic root replacement (Bentall) & 8 & 1.9 \\
\hline Aortic valve replacement & 5 & 1.2 \\
\hline Mitral valve repair & 3 & 0.7 \\
\hline Maze procedure & 9 & 2.1 \\
\hline Abdominal aortic replacement & 5 & 1.2 \\
\hline \multicolumn{3}{|l|}{ Cannulation sites/type for $\mathrm{CPB}$} \\
\hline Ascending aorta/arch & 320 & 75.7 \\
\hline Femoral artery & 68 & 16.1 \\
\hline Axillary artery & 1 & 0.2 \\
\hline Femoral artery + axillary artery & 8 & 1.9 \\
\hline Ascending aorta + femoral artery & 24 & 5.7 \\
\hline Others & 2 & 0.5 \\
\hline 24F dispersion & 196 & 46.3 \\
\hline \multicolumn{3}{|l|}{ 30-d mortality } \\
\hline Overall & $12 / 423$ & $2.8 \%$ \\
\hline Elective cases & $2 / 288$ & $0.69 \%$ \\
\hline Nonelective cases & $10 / 135$ & $7.4 \%$ \\
\hline Acute type A aortic dissection & $6 / 75$ & $8.0 \%$ \\
\hline Elective nondissection & $2 / 231$ & $0.87 \%$ \\
\hline \multicolumn{3}{|l|}{ Hospital death } \\
\hline Overall & $19 / 423$ & $4.5 \%$ \\
\hline Elective cases & $6 / 288$ & $2.1 \%$ \\
\hline Nonelective cases & $13 / 135$ & $9.6 \%$ \\
\hline Acute type A aortic dissection & $7 / 75$ & $9.3 \%$ \\
\hline Elective nondissection & $5 / 231$ & $2.2 \%$ \\
\hline
\end{tabular}

$S D$, Standard deviation; $L V E F$, left ventricular ejection fraction; $C O P D$, chronic obstructive pulmonary disorder; euroSCORE, European System for Cardiac Operative Risk Evaluation; $C P B$, cardiopulmonary bypass.

Thereafter, the lower body circulation was reinstituted through 1 branch of the graft, and whole body rewarming was started. At this stage, secure hemostasis in the distal suture line had to be obtained. Coincident with rewarming, the antegrade SCP flow was gradually increased while maintaining baseline values of $\mathrm{rSO}_{2}$. However, antegrade SCP flow was kept at less than $1200 \mathrm{~mL} / \mathrm{min}$ to prevent brain edema.

The proximal anastomosis was then accomplished using 4-0 sutures, a 17-mm needle, and monofilament sutures with 10-mm-wide Teflon felt reinforcement. After deairing the heart, the graft clamp was released, coronary reperfusion was started, and the heart was defibrillated if necessary (Figure 5, A).

The aortic arch was divided to make arch vessel buttons, each with a traction suture (Figure 5, B). Three arch vessels were reconstructed tandem to the graft branches using 5-0 monofilament sutures with a $17-\mathrm{mm}$ needle. The parachute technique was usually used, and each vessel was perfused after completion of the anastomosis (Figure 5,C); then the patient was weaned from $\mathrm{CPB}$. The left pleura were opened longitudinally near the sternum to monitor any unexpected bleeding into the left pleural cavity.

If arch vessel patients also had carotid artery or intracranial artery stenosis/occlusion, then reconstruction was performed before rewarming. The fluid balance during CPB was strictly controlled and kept at less than $1000 \mathrm{~mL}$ by the extracorporeal ultrafiltration method (Capiox Hemoconcentrator HC11; Terumo Corp). The other concurrent procedures performed are shown in Table 1.

\section{Definition of Neurologic Deficits}

Permanent neurologic dysfunction was defined as the presence of deficits that persisted at discharge that were caused by an intraoperative procedure. Transient dysfunction was defined as the transient loss of orientation, slurred language, agitation, or a poor response to commands. Neurologic dysfunction caused by preoperative brain malperfusion associated with acute type A dissection, deep shock status, or postoperative atrial fibrillation was excluded from this category. ${ }^{8}$ Brain malperfusion was defined as cerebral blood flow disturbance secondary to acute aortic dissection involving aortic arch branches with newly developed stroke, transient ischemic attack, or consciousness disorder.

\section{Statistical Analysis}

Data were processed using the Stat View J-5.0 software program (SAS Institute Inc, Cary, NC). Continuous values are expressed as mean \pm standard deviation. Data were analyzed by the chi-square test for categoric variables. A stepwise logistic regression analysis was performed to identify risk factors for hospital mortality, permanent neurologic deficit (PND), and transient neurologic deficit (TND). Clinically relevant variables with a $P$ value less than .05 in the univariate analysis were incorporated into the multivariate models. Survival and freedom from aortic aneurysm-related death were assessed by the Kaplan-Meier method.

\section{RESULTS}

The average CPB time was $183.3 \pm 72.9$ minutes, average myocardial ischemic time was $88.1 \pm 56.2$ minutes, average lower body CA time was $41.1 \pm 29.7$ minutes, average SCP time was $93.1 \pm 34.4$ minutes, and minimum tympanic and rectal temperatures were $23.5^{\circ} \mathrm{C} \pm 2.7^{\circ} \mathrm{C}$ and $26.9^{\circ} \mathrm{C} \pm 3.0^{\circ} \mathrm{C}$, respectively. The 30 -day mortality was $2.8 \%(12 / 423)$. The 30 -day mortality was $7.4 \%(10 / 135)$ in urgent/emergency surgery cases and $0.69 \%(2 / 288)$ in elective cases. The hospital mortality rate was $4.5 \%$ (19/423). The hospital mortality rate was 9.6\% (13/135) in the urgent/emergency surgery cases and $2.1 \%(6 / 288)$ in elective cases. The causes of death were central nervous system in 7 patients, sepsis in 2 patients, necrosis of the intestine in 2 patients, pulmonary problems in 6 patients, and hemorrhage in 2 patients. A multivariate analysis 


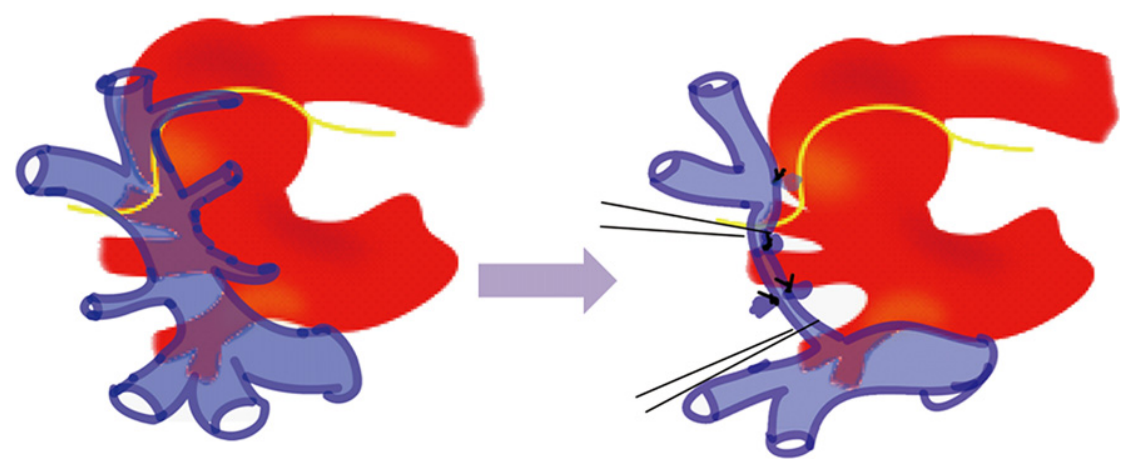

FIGURE 1. Mobilization of the innominate vein.

demonstrated that the risk factors for hospital mortality were age (octogenarian; odds ratio [OR], 4.45; $P=.03$ ), brain malperfusion due to acute aortic dissection (OR, 23.52; $P=.002)$, and $\mathrm{CPB}$ time (OR, $1.07 ; P=.04$; Table 2).

A new PND occurred in 23 patients $(5.4 \%)$ after surgery and in 8 patients $(3.4 \%)$ who underwent elective operation. An additional 5 patients had a neurologic deficit preoperatively, caused by brain malperfusion in 4 and by deep shock in 1, resulting from left main trunk malperfusion associated with acute type A aortic dissection. Three patients had a stroke secondary to postoperative atrial fibrillation. The multivariate analysis for PND disclosed that the preoperative leukoaraiosis score and presence of a shaggy aorta were significant risk factors. A calcified aorta and stenotic/obstructive lesion in the carotid arteries were not risk factors for PND (Table 3). A TND occurred in 37 patients $(8.7 \%)$ after surgery, and $10(2.4 \%)$ of these patients underwent elective operation. The multivariate analysis demonstrated that risk factors for TND were a shaggy aorta $(\mathrm{OR}, 3.89 ; P=.02)$ and low left ventricular ejection fraction $(\leq 40 \%)(\mathrm{OR}, 4.56 ; P=.05$; Table 4$)$. Additional postoperative complications are shown in Table 5. The mean mechanical ventilation time was $23.2 \pm 39.7$ hours. With regard to the respiratory complications, 57 patients $(13.4 \%)$ required prolonged mechanical ventilation ( $\geq 48$ hours).

Follow-up was completed in $97.2 \%$ of the patients, and the mean follow-up period was $2.3 \pm 2.3$ years. Late death occurred in 51 patients, and the causes of death were pneumonia in 19 , malignancy in 8 , cardiac events in 7 , cerebrovascular events in 5, aorta-related events in 4 , gastrointestinal problems in 3 , renal failure in 2 , and other causes in 3 . There were 4 patients who died of aorta-related events during the follow-up period. The causes of death were rupture of a penetrating atherosclerotic ulcer in the descending aorta 1 year after total arch replacement (TAR), rupture of a thoracoabdominal aortic aneurysm 3 years after TAR, sudden death with hemoptysis presumably caused by an aortopulmonary fistula, and sudden death of unknown cause 4 months after TAR. The overall longterm survival was assessed by the Kaplan-Meier method. The survival at 5 and 10 years after surgery was $79.6 \% \pm 3.3 \%$ and $71.2 \% \pm 5.0 \%$, respectively. Survival at 10 years was $96.6 \% \pm 2.4 \%$ in the acute type A dissection group and $76.1 \% \pm 5.7 \%$ in the elective nondissection group. The rates of freedom from aorta-related death at 3 and 5 years after surgery were $89.1 \% \pm 4.2 \%$ and $80.9 \% \pm 3.5 \%$, respectively. We identified 4 factors that decreased late survival. These factors were age more than 80 years, organ malperfusion caused by acute aortic dissection, chronic kidney disease, and a longer operation time. Acute aortic dissection itself was a protective factor. Twentythree patients required repeat (17) or additional (6) aortic surgery. Repeat surgery was necessary in 2 patients who had proximal false aneurysm secondary to gelatinresorcin-formalin glue necrosis, in 2 who had distal false

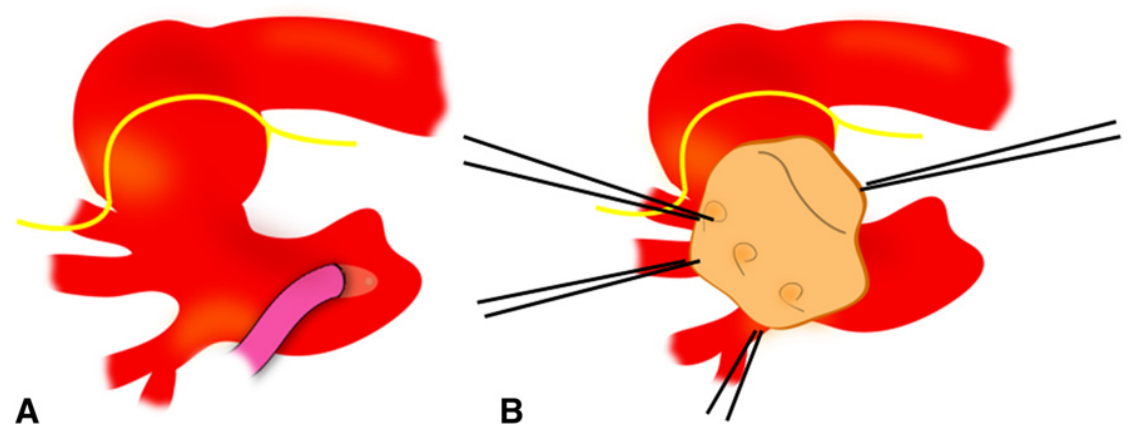

FIGURE 2. A, Aortic cannulation without taping or arch dissection. B, Aortic arch is opened with 4 traction sutures under CA. 


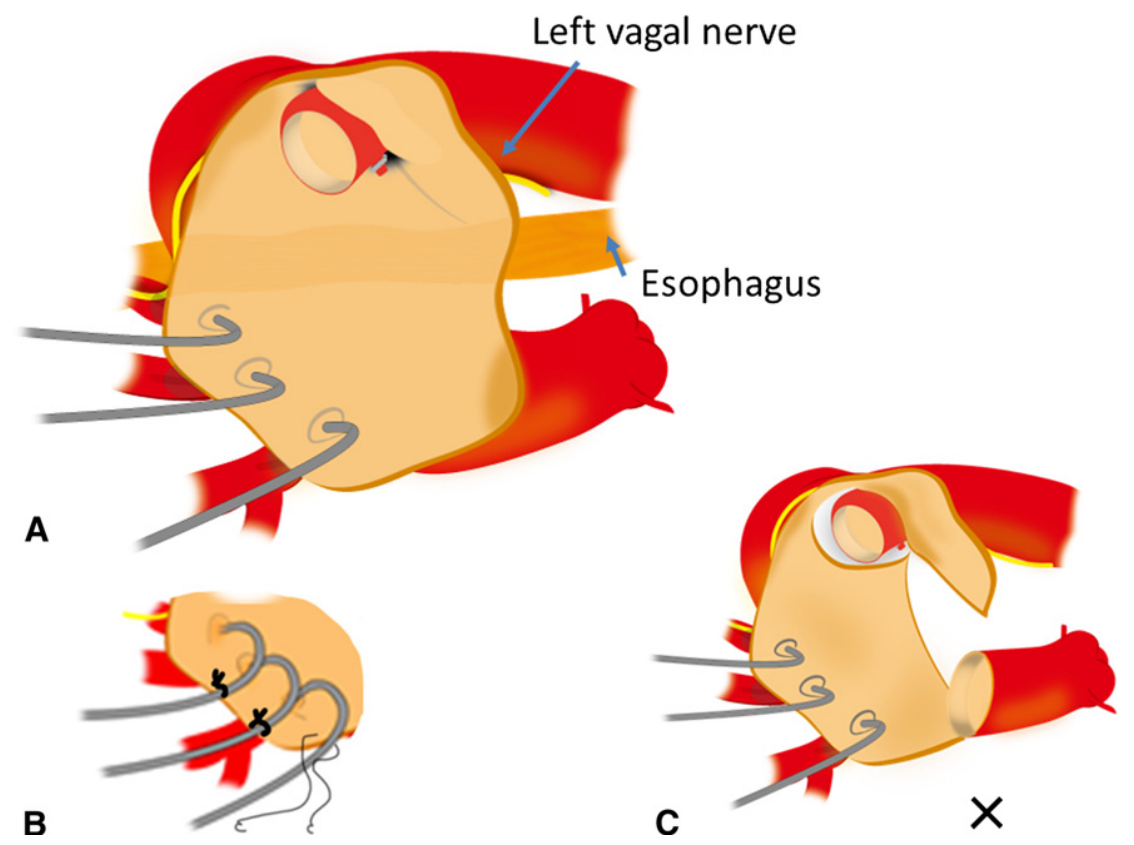

FIGURE 3. A, Antegrade SCP from inside the aortic arch with transection of the descending aorta. B, Fixation of the cannulae. C, Incision of the aortic wall was not applied.

aneurysm and in 2 with elephant trunk infection or kinking. Freedom from repeat aortic surgery was $98.2 \% \pm 1.5 \%$ at 5 years and $91.3 \% \pm 4.1 \%$ at 10 years. Additional surgery consisted of aortic root/valve reconstruction in 3 patients, replacement of the descending aorta in 3 patients, replacement of the thoracoabdominal aorta in 7 patients, and thoracic endovascular aortic repair in 5 patients. Freedom from additional aortic surgery was $93.4 \% \pm 2.5 \%$ and $82.5 \% \pm 5.7 \%$ at 5 and 10 years, respectively.

\section{DISCUSSION}

Recent advances in surgery for the aortic arch are becoming widely recognized. This achievement has been attributed to the development of water-sealed grafts, the evolution of CPB techniques and equipment, better understanding of brain protection, and refinement of the surgical procedures. ${ }^{9,10}$ We have recently published our experience with surgery for the aortic arch. ${ }^{7}$ We found the risk factors for early mortality in patients who underwent total arch

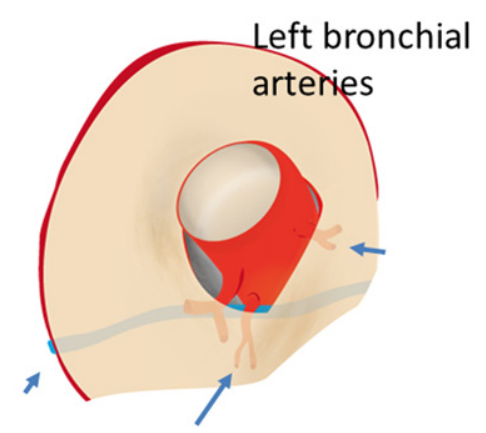

\section{Thoracic duct Right bronchial arteries}

\section{A}

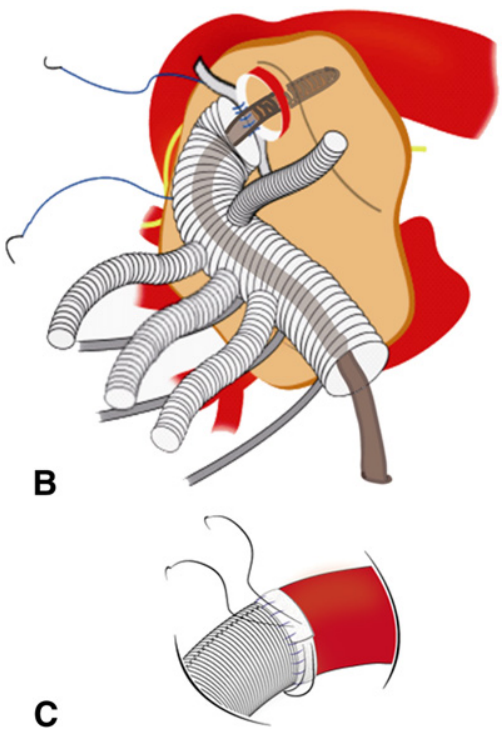

FIGURE 4. A, Division of the bronchial arteries and mobilization of the descending aorta. B, Distal anastomosis under CA of the lower body. A flexible sucker was placed inside the graft. C, Compacting stitch was placed to fasten the Teflon felt. 


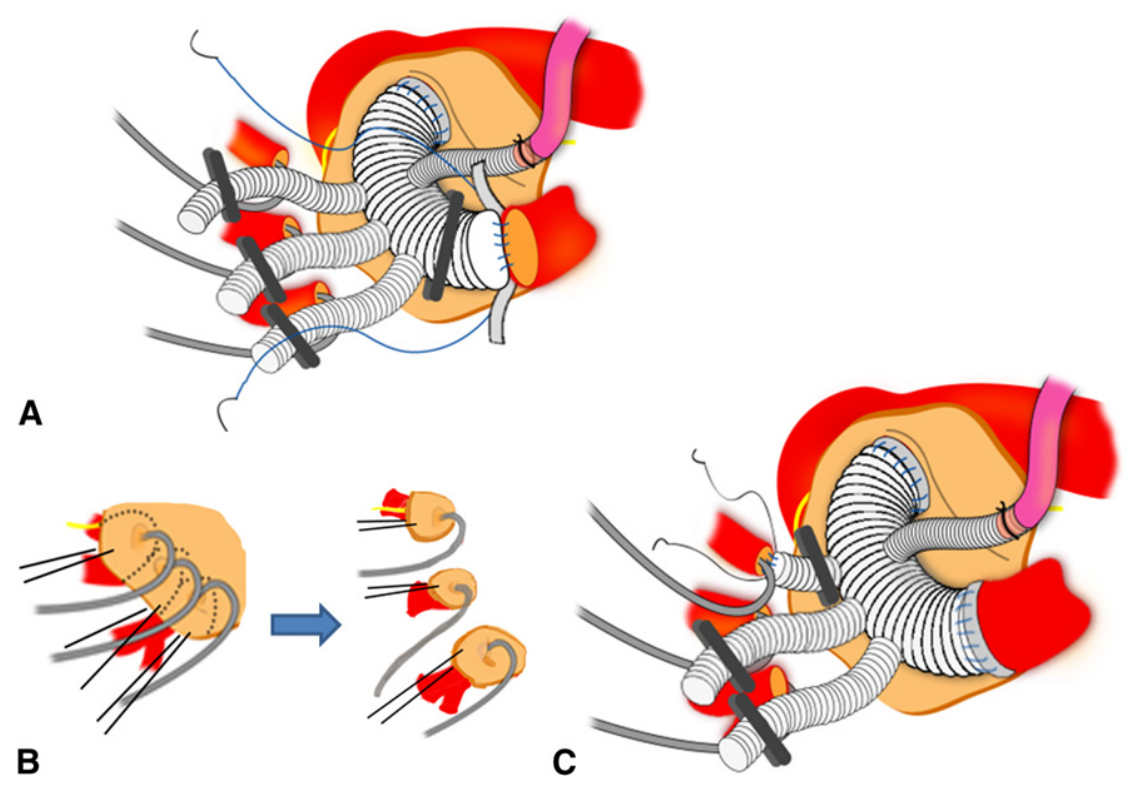

FIGURE 5. A, Lower body reperfusion through the branch graft and early rewarming while monitoring NIRS, followed by proximal anastomosis. B, Division of the arch vessels and making buttons. C, Anastomosis of the arch vessels while continuing antegrade cerebral perfusion.

replacement to be octogenarian age, preoperative brain malperfusion, and prolonged CPB. In elective patients without an aortic dissection, the risk factors for postoperative stroke were leukoaraiosis indicated by the magnetic resonance imaging scan and a shaggy aorta. With regard to transient neurologic dysfunction in these patients, the risk factors were

TABLE 2. Risk factors for hospital mortality identified by univariate and multivariate analyses

\begin{tabular}{|c|c|c|c|c|}
\hline \multirow[b]{2}{*}{ Variables } & \multicolumn{2}{|l|}{ Univariate } & \multicolumn{2}{|l|}{ Multivariate } \\
\hline & OR $(95 \%$ CI $)$ & $\boldsymbol{P}$ & OR $(95 \%$ CI $)$ & $P$ \\
\hline Octogenarian & $3.09(1.03-9.23)$ & .04 & $4.32(1.19-15.7)$ & .03 \\
\hline Male gender & $0.65(0.21-2.02)$ & .46 & & \\
\hline Dissection & $1.87(0.63-5.54)$ & .26 & & \\
\hline Brain malperfusion & $30.3(6.61-138.9)$ & $<.0001$ & $21.2(3.47-130.1)$ & .001 \\
\hline Shaggy aorta & $1.34(0.29-6.24)$ & .71 & & \\
\hline Emergency/urgent & $5.50(1.68-18.0)$ & .005 & $2.31(0.56-9.55)$ & .25 \\
\hline Rupture & $1.97(0.42-9.30)$ & .39 & & \\
\hline Shock & $2.88(0.33-24.7)$ & .34 & & \\
\hline Diabetes mellitus & $0.58(0.07-4.56)$ & .60 & & \\
\hline Old cerebral infarction & $2.61(0.69-9.91)$ & .16 & & \\
\hline Coronary artery disease & $2.74(0.92-8.17)$ & .07 & & \\
\hline Low LVEF $(\leq 40 \%)$ & $2.29(0.27-19.2)$ & .44 & & \\
\hline COPD & $2.27(0.48-10.8)$ & .30 & & \\
\hline CKD & $2.06(0.43-9.76)$ & .36 & & \\
\hline Concurrent procedure & $1.23(0.42-3.63)$ & .71 & & \\
\hline CPB time & $1.01(1.00-1.01)$ & .006 & $1.01(1.00-1.01)$ & .04 \\
\hline Tympanic temperature & $0.81(0.57-1.14)$ & .81 & & \\
\hline $\begin{array}{l}\text { Fluid balance during } \\
\text { CPB }\end{array}$ & $1.0(1.0-1.0)$ & .95 & & \\
\hline
\end{tabular}

a shaggy aorta, leukoaraiosis, extracranial stenosis of the carotid arteries, and prolonged $\mathrm{CPB} .{ }^{11}$

As for the surgical approaches to the aneurysm, especially for a distal arch aneurysm, both a midsternotomy and left thoracotomy can be applied. However, we have used midsternotomy exclusively to avoid several complications that may occur more frequently with left thoracotomy. For example, patients with chronic obstructive lung disease

TABLE 3. Risk factors for permanent neurologic deficit identified by univariate analysis

\begin{tabular}{lcc}
\hline \multirow{2}{*}{\multicolumn{1}{c}{ Variables }} & \multicolumn{1}{c}{ Univariate } \\
\cline { 2 - 3 } \multicolumn{1}{c}{ OR $(\mathbf{9 5} \% \mathbf{C I})$} & $\boldsymbol{P}$ \\
\hline Octogenarian & $1.06(0.29-3.90)$ & .93 \\
Male gender & $1.38(0.38-5.07)$ & .63 \\
Dissection & $1.87(0.63-5.53)$ & .16 \\
Emergency/urgent & $2.84(0.96-8.42)$ & .06 \\
Rupture & $3.37(0.88-12.9)$ & .08 \\
Shock & $2.99(0.34-26.4)$ & .32 \\
Diabetes mellitus & $0.58(0.07-4.56)$ & .58 \\
Old cerebral infarction & $1.54(0.33-7.21)$ & .58 \\
Coronary artery disease & $1.41(0.43-4.62)$ & .57 \\
CKD & $2.06(0.43-9.76)$ & .36 \\
Concurrent procedure & $1.23(0.42-3.63)$ & .71 \\
CPB time & $1.004(1.00-1.01)$ & .25 \\
SCP time & $1.01(1.00-1.02)$ & .11 \\
Tympanic temperature & $1.06(0.79-1.42)$ & .70 \\
Fluid balance during CPB & $1.0(1.0-1.0)$ & .14 \\
Use of 24F dispersion cannula & $0.72(0.24-2.22)$ & .58 \\
\hline
\end{tabular}

Variables of shaggy aorta, shock status, low LVEF, and COPD were not tested because PND did not occur in cases with the factors. $O R$, Odds ratio; $C I$, confidence interval; $C K D$, chronic kidney disease (creatinine $\geq 2.0$ ); $C P B$, cardiopulmonary bypass; $S C P$, selective cerebral perfusion. 
TABLE 4. Risk factors for transient neurologic deficit identified by univariate and multivariate analyses

\begin{tabular}{|c|c|c|c|c|}
\hline \multirow[b]{2}{*}{ Variables } & \multicolumn{2}{|c|}{ Univariate } & \multicolumn{2}{|l|}{ Multivariate } \\
\hline & OR $(95 \%$ CI $)$ & $P$ & OR $(95 \%$ CI $)$ & $P$ \\
\hline Octogenarian & $1.22(0.43-3.47)$ & .70 & & \\
\hline Male gender & $2.33(0.67-8.12)$ & .18 & & \\
\hline Dissection & $0.11(0.02-0.84)$ & .04 & $0.48(0.05-5.00)$ & .54 \\
\hline Shaggy aorta & $9.58(3.72-24.7)$ & $<.0001$ & $3.73(1.26-11.1)$ & .018 \\
\hline Emergency/urgent & $0.20(0.05-0.87)$ & .04 & $0.73(0.13-4.09)$ & .72 \\
\hline Rupture & $0.55(0.07-4.27)$ & .57 & & \\
\hline Diabetes mellitus & $0.80(0.18-3.57)$ & .77 & & \\
\hline Old cerebral infarction & $1.56(0.43-5.61)$ & .50 & & \\
\hline Coronary artery disease & $4.31(1.75-10.6)$ & .002 & $2.36(0.45-12.3)$ & .31 \\
\hline Low LVEF $(\leq 40 \%)$ & $9.85(2.63-37.0)$ & .0007 & $4.90(1.00-23.9)$ & .05 \\
\hline COPD & $4.90(1.61-14.9)$ & .05 & $2.04(0.54-7.75)$ & .30 \\
\hline CKD & $3.13(0.96-10.1)$ & .05 & & \\
\hline Concurrent procedure & $2.83(1.14-7.05)$ & .03 & $0.80(0.15-4.20)$ & .79 \\
\hline CPB time & $1.00(1.00-1.01)$ & .27 & & \\
\hline SCP time & $0.99(0.98-1.01)$ & .45 & & \\
\hline Tympanic temperature & $0.89(0.68-1.16)$ & .77 & & \\
\hline $\begin{array}{l}\text { Use of } 24 \mathrm{~F} \text { dispersion } \\
\text { cannula }\end{array}$ & $6.29(0.24-2.22)$ & .001 & $2.49(0.71-8.76)$ & .16 \\
\hline
\end{tabular}

A variable of shock status was not tested because PND did not occur in cases associated with shock. $O R$, Odds ratio; $C I$, confidence interval; $L V E F$, left ventricular ejection fraction; $C O P D$, chronic obstructive pulmonary disease; $C K D$, chronic kidney disease (creatinine $\geq 2.0$ ); $C P B$, cardiopulmonary bypass; $S C P$, selective cerebral perfusion.

or chronic aortic dissection tend to have adhesions between the aneurysm and the left lung. Lung injury secondary to surgical manipulation, especially after deep hypothermia, can add a further risk for postoperative pulmonary complications. ${ }^{12}$ In addition, the incidence of left recurrent nerve damage was higher in patients who underwent a left thoracotomy than with midsternotomy. In regard to the proximal control of the aneurysm, aortic arch clamping or deep hypothermic CA is usually required during left thoracotomy, and this may add some risk of postoperative brain complications. We previously reported that the level of the carina,

TABLE 5. Additional postoperative complications

\begin{tabular}{lc}
\hline \multicolumn{1}{c}{ Variables } & No. $(\%)$ \\
\hline Paraplegia & $3(0.9)$ \\
Temporary & $1(0.3)$ \\
Permanent & $2(0.6)$ \\
Paraparesis & $1(0.3)$ \\
Temporary & $1(0.3)$ \\
Mediastinitis & $7(2.4)$ \\
Mean mechanical ventilation time (h) & $26.5 \pm 46.4$ \\
Prolonged ventilation $(\geq 48 \mathrm{~h})$ & $53(16.5)$ \\
Prolonged ventilation after 2006 & $25(12.6)$ \\
Renal failure & $10(3.1)$ \\
Gastrointestinal tract & $8(2.5)$ \\
Bleeding & $6(1.9)$ \\
Necrosis & $2(0.6)$ \\
\hline
\end{tabular}

$* P=.02$ versus before 2006 . or $17 \mathrm{~cm}$ from the sternum level to the back, was approachable via a midsternotomy. ${ }^{13}$

Dissection of the aortic arch was limited only to the anterior aspect of the aortic arch. The left vagal nerve should not be dissected, because once the nerve has been dissected, then injury to the neighboring blood vessel can occur and secondary insults to the nerve then ensue. In addition, dissection or taping of the arch vessels is not necessary, because the serrated balloon-tipped cannulae are usually well situated in the neck vessels without snaring. However, if they are not properly positioned, the cannulae can be simply fixed with a silk suture near the orifice of the neck vessels.

The selection of the arterial cannulation site and the type of cannula are important in preventing atheroembolic events, particularly neurologic complications. In most instances, we selected the ascending aorta as the arterial cannulation site after inspection of the epiaortic echocardiographic scan. Grooters and colleagues ${ }^{14}$ described the advantages of arterial perfusion toward the aortic valve. In an experimental study, Fukuda and colleagues ${ }^{15}$ confirmed that directing the cannula tip of the dispersion cannula toward the aortic root generated slower and less turbulent flow in the transverse arch of glass models of both healthy and aneurysmal aortic arches. Even in patients with mild to moderate aortic regurgitation, we usually point the cannula toward the aortic valve. Because the left ventricular venting catheter was properly positioned, we found no serious dilatation of the left ventricle after fibrillation.

Antegrade cerebral perfusion is now considered to be the most reliable brain protection method and has been widely used in the field of aortic surgery. ${ }^{2,16,17}$ However, the procedures vary among surgeons. We always use 3 cannulae that are inserted from inside of the arch without snaring. Urbanski and colleagues ${ }^{18}$ have used only 2 cannula to perfuse the whole brain and reported a low incidence of postoperative stroke. Many surgeons perfuse only the brachiocephalic and left common carotid artery, and not the left subclavian artery. ${ }^{9}$ However, the incompleteness of the circle of Willis has been reported to be as high as $20 \%$ to $30 \%$ in the healthy population, ${ }^{19}$ and the vertebral arteries are sometimes hypoplastic or stenotic, especially in elderly patients. In addition, the left subclavian artery is often a supplier of the collateral vessels to the spinal cord.

Cannulation in the axillary artery has become popular for treating patients with acute type A aortic dissection or a shaggy ascending aorta, because this cannulation can provide antegrade blood flow in the aortic arch. ${ }^{20}$ Nevertheless, there still are some concerns remaining for patients who have atheromatous or ulcerative lesions at the orifices of the aortic arch vessels. If perfused from the right axillary artery, this fragile debris tends to embolize distally. In such cases, we incise the arch vessels distally and cannulate in the normal portion of the artery. ${ }^{21}$ 
As noted by Kouchoukos and colleagues ${ }^{22}$ the exclusion technique for aortic anastomosis or aortic branches is more secure than the inclusion technique. We always transect the aorta just distal to the aneurysm and divide several bronchial arteries. This also may alleviate inadvertent injury to the esophagus or left lung. Technically, the transection of the aorta is usually performed by making the incision circumferentially from inside the aorta, not by incising the aortic arch wall anteriorly or posteriorly. The left vagal nerve and left recurrent nerve should not be touched.

A 4-branch graft has several advantages over the island aortic cuff technique when used to reconstruct the arch vessels. ${ }^{2,10}$ The individual anastomosis of each arch vessel can provide a secure anastomosis. In addition, by dividing the arch cuff into 3 buttons, more liberal exposure of the aortic arch can be obtained. Consequently, proximal anastomosis of the ascending aorta can precede the arch anastomosis and result in a reduction in the cardiac ischemic time. Some risk factors for stroke in connection with aortic surgery have been identified.

Although aortic pathology has not been included in preoperative risk stratification systems, such as the European System for Cardiac Operative Risk Evaluation system, it is apparently one of the risk factors for an adverse neurologic outcome. Our group previously reported that the severity of aortic arch atheroma has been identified as another risk factor for adverse neurologic outcomes. ${ }^{11} \mathrm{~A}$ shaggy aorta is associated with extensive friable and soft atheromatous lesions. Amarenco and colleagues ${ }^{23}$ indicated that there was a strong, independent association between atherosclerotic disease of the aortic arch and the risk of ischemic stroke, particularly in patients with thick plaque $(\geq 4 \mathrm{~mm}$ ). There were 37 patients with a shaggy aorta in this study. No patients had PND, and 10 patients $(27.8 \%)$ had TND. A multivariate analysis demonstrated that a shaggy aorta was a risk factor for TND, but not for PND. In the present study, meticulous selection of the cannulation site and the type of cannula based on the accurate preoperative and intraoperative imaging of the aortic pathology and complete exclusion of the diseased aorta contributed to avoiding PND, even in cases with a shaggy aorta.

The temperature of hypothermic CA during the distal anastomosis is particularly crucial for protecting vital organs. Because the primary goal of core cooling is to achieve a brain temperature compatible with the maximum suppression of metabolism, the lowest temperatures that can be safely achieved are used for optimal brain protection. ${ }^{16}$ On the other hand, deep hypothermia tends to be associated with coagulopathy or lung injury, which is to be avoided. The optimal temperature used during antegrade SCP has been reported to be between $20^{\circ} \mathrm{C}$ and $28^{\circ} \mathrm{C}^{2,4,16}$ Kamiya and colleagues ${ }^{24}$ reported that the temperature during hypothermic CA could safely be increased to $28^{\circ} \mathrm{C}$ with a high SCP flow rate, and that the incidence of neurologic events was not increased. We set the tympanic temperature between $20^{\circ} \mathrm{C}$ and $23^{\circ} \mathrm{C}$, thus resulting in optimal $\mathrm{CA}$ and SCP times $(42.4 \pm 27.8$ minutes and $97.3 \pm 31.4$ minutes, respectively). We aim to keep the rectal temperature at less than $30^{\circ} \mathrm{C}$ just before $\mathrm{CA}$, because necrosis of the entire colon developed in 1 patient whose rectal temperature before CA was in excess of $30^{\circ} \mathrm{C}$, presumably because of the presence of the calcified stenosis of the mesenteric artery with poor visceral circulation.

To minimize CPB time, we start rewarming as soon as the distal anastomosis is completed, with concurrent antegrade distal reperfusion to the lower body through the prosthetic graft branch. We then move to the proximal anastomosis, and usually immediately after the arch vessel anastomosis, $\mathrm{CPB}$ can be terminated. Monitoring brain oxygenation during rewarming is particularly important. We increase the SCP flow from 10 to $15 \mathrm{~mL} / \mathrm{min} / \mathrm{m}^{2}$ to maintain preoperative values of NIRS ${ }^{25}$; however, total flow was always maintained at less than $1200 \mathrm{~mL} / \mathrm{min}$ to avoid brain edema.

\section{CONCLUSIONS}

The technical details of our TAR technique have been presented. Our approach for TAR has contributed to low hospital mortality and morbidity, thus leading to a favorable long-term outcome.

\section{References}

1. Svensson LG, Crawford ES, Hess KR, Coselli JS, Raskin S, Shenaq SA, et al. Deep hypothermia with circulatory arrest. Determinants of stroke and early mortality in 656 patients. $J$ Thorac Cardiovasc Surg. 1993;106:19-28.

2. Strauch JT, Spielvogel D, Lauten A, Galla JD, Lansman SL, McMurtry K, et al. Technical advances in total aortic arch replacement. Ann Thorac Surg. 2004;77: 581-90.

3. Ueda Y, Miki S, Kusuhara K, Okita Y, Tahata T, Yamanaka K. Surgical treatment of aneurysm or dissection involving the ascending aorta and aortic arch, utilizing circulatory arrest and retrograde cerebral perfusion. J Cardiovasc Surg (Torino). 1990;31:553-8.

4. Kazui T, Washiyama N, Muhammad BA, Terada H, Yamashita K, Takinami M. Improved results of atherosclerotic arch aneurysm operations with a refined technique. J Thorac Cardiovasc Surg. 2001;121:491-9.

5. Kuwano H, Amano J, Yokomise H. Thoracic and cardiovascular surgery in Japan during 2010: annual report by the Japanese Association for Thoracic Surgery. Committee for Scientific Affairs. Gen Thorac Cardiovasc Surg. 2012;60: 680-708.

6. Hollier LH, Kazmier FJ, Ochsner J, Bowen JC, Procter CD. Shaggy aorta syndrome with atheromatous embolization to visceral vessels. Ann Vasc Surg. 1991;5:439-44.

7. Okada K, Omura A, Kano H, Sakamoto T, Tanaka A, Inoue T, et al. Recent advancements of total aortic arch replacement. J Thorac Cardiovasc Surg. 2012; 144:139-45.

8. Ergin MA, Uysal S, Reich DL, Apaydin A, Lansman SL, McCullough JN, et al. Temporary neurological dysfunction after deep hypothermic circulatory arrest: a clinical marker of long-term functional deficit. Ann Thorac Surg. 1999;67: 1887-90.

9. Ogino H, Sasaki H, Minatoya K, Matsuda H, Tanaka H, Watanuki H, et al. Evolving arch surgery using integrated antegrade selective cerebral perfusion: impact of axillary artery perfusion. J Thorac Cardiovasc Surg. 2008;136:641-8.

10. Kazui T, Yamashita K, Washiyama N, Terada H, Bashar AH, Suzuki K, et al. Aortic arch replacement using selective cerebral perfusion. Ann Thorac Surg. 2007; 83:S796-8.

11. Morimoto N, Okada K, Uotani K, Kanda F, Okita Y. Leukoaraiosis and hippocampal atrophy predict neurologic outcome in patients who undergo total aortic arch replacement. Ann Thorac Surg. 2009;88:476-81. 
12. Asimakopoulos G, Smith PL, Ratnatunga CP, Taylor KM. Lung injury and acute respiratory distress syndrome after cardiopulmonary bypass. Ann Thorac Surg. 1999;68:1107-15.

13. Asano M, Okada K, Nakagiri K, Tanaka H, Kawanishi Y, Matsumori M, et al. Total arch replacement for aneurysm of the aortic arch: factors influencing the distal anastomosis. Interact Cardiovasc Thorac Surg. 2007;6:283-7.

14. Grooters RK, Thieman KC, Schneider RF, Nelson MG. Assessment of perfusion toward the aortic valve using the new dispersion aortic cannula during coronary artery bypass surgery. Tex Heart Inst J. 2000;27:361-5.

15. Fukuda I, Fujimori S, Daitoku K, Yanaoka H, Inamura T. Flow velocity and turbulence in the transverse aorta of a proximally directed aortic cannula: hydrodynamic study in a transparent model. Ann Thorac Surg. 2009;87:1866-71.

16. Bachet J, Guilmet D, Goudot B, Dreyfus GD, Delentdecker P, Brodaty D, et al. Antegrade cerebral perfusion with cold blood: a 13-year experience. Ann Thorac Surg. 1999;67:1874-8

17. Okita Y, Minatoya K, Tagusari O, Ando M, Nagatsuka K, Kitamura S. Prospective comparative study of brain protection in total aortic arch replacement: deep hypothermic circulatory arrest with retrograde cerebral perfusion or selective antegrade cerebral perfusion. Ann Thorac Surg. 2001;72:72-9.

18. Urbanski PP, Lenos A, Lindemann Y, Weigang E, Zacher M, Diegeler A. Carotid artery cannulation in aortic surgery. J Thorac Cardiovasc Surg. 2006;132: 1398-403.
19. Merkkola P, Tulla H, Ronkainen A, Soppi V, Oksala A, Koivisto T, et al. Incomplete circle of Willis and right axillary artery perfusion. Ann Thorac Surg. 2006; 82:74-9.

20. Strauch JT, Spielvogel D, Lauten A, Lansman SL, McMurtry K, Bodian CA, et al Axillary artery cannulation: routine use in ascending aorta and aortic arch replacement. Ann Thorac Surg. 2004;78:103-8.

21. Minakawa M, Fukuda I, Inamura T, Yanaoka H, Fukui K, Daitoku K, et al Hydrodynamic evaluation of axillary artery perfusion for normal and diseased aorta. Gen Thorac Cardiovasc Surg. 2008;56:215-21.

22. Kouchoukos NT, Wareing TH, Murphy SF, Perrillo JB. Sixteen-year experience with aortic root replacement. Results of 172 operations. Ann Surg. 1991;214 308-18.

23. Amarenco P, Cohen A, Tzourio C, Bertrand B, Hommel M, Besson G, et al. Atherosclerotic disease of the aortic arch and the risk of ischemic stroke. $N$ Engl J Med. 1994;331:1474-9.

24. Kamiya H, Hagl C, Kropivnitskaya I, Böhig D, Kallenbach K, Khaladj N, et al The safety of moderate hypothermic lower body circulatory arrest with selective cerebral perfusion: a propensity score analysis. J Thorac Cardiovasc Surg. 2007; 133:501-9.

25. Olsson C, Thelin S. Regional cerebral saturation monitoring with near-infrared spectroscopy during selective antegrade cerebral perfusion: diagnostic performance and relationship to postoperative stroke. J Thorac Cardiovasc Surg. 2006;131:371-9. 